AL-URBAN: Jurnal Ekonomi Syariah dan Filantropi Islam

Vol. 3, No. 1, Juni 2019

http://journal.uhamka.ac.id/index.php/al-urban

p-ISSN: 2580-3360 e-ISSN: 2581-2874

DOI: $10.22236 /$ alurban_vol3/is1pp1-12

Hal 1-12

\title{
RELIGIUSITAS DAN PENGARUH FAKTOR DEMOGRAFI TERHADAP KEPATUHAN DALAM BERZAKAT
}

\author{
Ivalaili \\ UIN Syarif Hidayatullah Jakarta \\ Email: ivalaili@hotmail.com
}

Diterima: 12 Maret 2019; Direvisi:10 Juni 2019 ; Disetujui: 19 Juni 2019

\begin{abstract}
Zakat is one of the essential instruments in increasing community welfare as well as enhancing economic growth. To optimize potential zakat in Indonesia, it needs the involvement of various related parties both government and zakat institution and participation of muzakki as well. Based on the previous study it is known that external and internal factors influencing people compliance to pay zakat, external factors could be arisen from the environment, organization/ zakat institution and the obligation, while internal factors could come from religious factors, such as faith, altruism, demographic factors and social awareness. Aim of this study is to examine the influence of religiosity, and demographic factors on zakat. The questionnaire was distributed to 300 muzakki in Kota Tangerang. The findings show that religiosity had significantly related to zakat compliance. Demographic factors in this case gender and educational background have no significant influence on zakat compliance but give a positive effect, while the level of income have both positive impacts and significantly influence on zakat compliance
\end{abstract}

Keyword: Religiosity, demographic factor, zakat compliance

\begin{abstract}
Abstrak
Zakat sebagai salah satu komponen utama dalam sistem ekonomi Islam yang dapat berfungsi secara efektif dalam menangani kemiskinan dan turut berperan dalam pertumbuhan ekonomi. Untuk mengoptimalkan potensi zakat di Indonesia diperlukan keterlibatan dari berbagai pihak yang terkait. Pihak terkait yang dimaksud adalah pemerintah maupun lembaga zakat baik nasional maupun swasta terlebih lagi peran muzakki sebagi pembayar zakat. Kepatuhan dalam berzakat dipengaruhi oleh faktor eksternal dan faktor internal. Faktor eksternal yaitu lingkungan, Institusi zakat dan juga peraturan maupun Undang- Undang, sementara faktor internal dipengaruhi oleh faktor religiusitas, altruism, faktor demografi dan faktor-faktor lainnya seperti kepedulian social. Tujuan dari penelitian in adalah untuk mengkaji pengaruh religiusitas dan faktor demografi dalam hal ini gender, latar belakang pendidikan dan tingkat pendapatan terhadap kepatuhan dalam berzakat. Kuesioner di distribusikan kepada 300 muzakki sebagai responden di Kota Tangerang. Hasil penelitian didapati bahwa religiusitas signifikan terhadap kepatuhan muzakki dalam berzakat, gender dan tingkat pendidikan tidak berpengaruh signifikan tetapi memiliki hubungan yang positif, sementara tingkat pendapatan memiliki pengaruh yang positif dan signifikan terhadap kepatuhan muzakki dalam berzakat.
\end{abstract}

Kata Kunci: Religiusitas, faktor demografi, kepatuhan berzakat 
Ivalaili - 2

\section{PENDAHULUAN}

Berdasarkan Undang-Undang Nomor 38

Tahun 1999 untuk mewujudkan tujuan nasional Indonesia dalam melaksanakan pembangunan, zakat merupakan salah satu sumber dana potensial yang dimanfaatkan untuk mewujudkan kesejahteraan masyarakat. Peranan zakat sesungguhnya tidak hanya terbatas pada pengentasan kemiskinan akan tetapi untuk mengatasi permasalahan-permasalahan sosial dan penyebab kemiskinan tersebut. Indonesia yang memiliki visi sebagai Negara pusat ekonomi Islam di dunia tahun 2024 turut menjadikan instrument zakat sebagai pilar pendukung dengan realisasi pengumpulan dana zakat mendekati potensinya. Pengelolaan dana zakat tidak terbatas hanya pada pengumpulan, akan tettapi mencakup aspek pengawasan, penyaluran dan pendayagunaannya. Efektivitas pengelolaan yang signifikan dapat memperbaiki kesejahteraan mustahik salah satunya dengan menjadikan zakat kearah lebih produktif, mentransformasi mustahik menjadi muzakki.

Pencapaian zakat di Indonesia dari tahun ke tahun terus meningkat pada tahun 2017 mencapai Rp. 6 triliun dimana mengalami peningkatan sebanyak 20 persen dari tahun 2016. BAZNAS merupakan Badan Amil Zakat Nasional yang telah dibentuk berdasarkan Keputusan Presiden No.8 Tahun 2001 memiliki tugas pokok mewujudkan misinya meningkatkan kesadaran umat dalam berzakat, hal tersebut tertuang dalam Strategi Klaster Utama Baznas Indonesia adalah peningkatan Awareness muzakki, masyarakat dan stakeholders tentang zakat (Sumber: Baznas 2018).

Penelitian mendapati bahwa kesadaran maupun kepatuhan dalam berzakat dipengaruhi oleh faktor eksternal dan faktor internal. Faktor eksternal yaitu lingkungan, organisasi zakat dalam hal ini Badan Amil Zakat ataupun Lembaga Amil Zakat dan peraturan maupun Undang-Undang. Sementara faktor internal salah satunya dipengaruhi oleh faktor religiusitas, faktor pemahaman agama maupun peribadahan.

Sebagai ibadah maliyah perintah berzakat di dalam Al-quran terdapat 81 ayat yang dituliskan secara eksplisit dan implisit, 29 ayat diantaranya bergandengan dengan perintah mendirikan shalat, perintah Allah SWT tentang zakat dalam Al-quran tersebut diartikan betapa pentingnya nilai ajaran zakat dalam Islam.

Muda et al. (2006) faktor utama yang seharusnya mempengaruhi seseorang berzakat adalah faktor peribadahan dalam kajiannya berpendapat seseorang yang menjaga kewajiban berzakat menandakan keimanan ada dalam dirinya. Penelitian Mukhlis dan Irfan (2013) faktor religiusitas menempati urutan pertana dalam mempengaruhi seseorang untuk membayar zakat, alas an terkuat seseorang mau membayar zakat karena di 
3 - AL-URBAN: Jurnal Ekonomi Syariah dan Filantropi Islam

Vol. 3, No. 1, Juni 2019

http://journal.uhamka.ac.id/index.php/al-urban

p-ISSN: 2580-3360 e-ISSN: 2581-2874

DOI: 10.22236/alurban_vol3/is1pp1-12

Hal 1-12

dorong oleh keimanannya, ia menyadari pentingnya berzakat bagi kehidupan dunia dan akhiratnya, ia juga menyadari bahwa perbuatan baiknya (seperti membayar zakat) pasti akan diberi balasan oleh Allah. Selanjutnya berbagai penelitian mengenai kepatuhan, sebagai contoh studi Collin et al. (1992) memperkenalkan pendekatan kontinjensi (contingency approach) kepatuhan terhadap membayar pajak dengan berbagai metode menyimpulkan bahwa kepatuhan seseorang didorong sejumlah faktor yang mempengaruhi perilaku individu. Faktor-faktor yang mempengaruhi perilaku kepatuhan antara lain usia, gender, tingkat pendidikan, tingkat pendapatan, komitmen moral, orientasi nilai. Pada penelitian berkaitan dengan kepatuhan berzakat telah mengidentifikasi bahwa tingkat religiusitas gender dan latar belakang pendidikan adalah faktor yang berkontribusu terhadap perilaku kepatuhan berzakat (Mohd. Rizuan et al. 2014). Berdasarkan permasalahan yang telah diuraikan di atas penelitian ini mencoba meneliti terbatas pada tingkat pendidikan dan tingkat pendapatan.

\section{KAJIAN LITERATUR}

\section{Religiusitas}

Dalam perspektif Islam, religiusitas merupakan aktivitas yang berhubungan dengan social, politik serta ekonomi dan aktivitas lain dalam berserah diri kepada Allah (Ancok dan Suroso, 2007:2) Dimensi religiusitas menurut Glock dan Stark (1993) dalam Ancok dan Suroso

(2007:77) ada lima diantaranya keyakinan, praktik, penghayatan, pengetahuan, konsekuensi. Wan Ahmad et al. (2008) menggunakan 22 religius item melalui dimensi inti keimanan, hokum islam, dan akhlaq, oleh karena itu penelitian ini berpendapat bahwa:

H1: Terdapat hubungan religiusitas dengan kepatuhan dalam berzakat.

\section{Gender}

Gender merupakan suatu konsep analisis yang digunakan untuk mengidentifikasi perbedaan lelaki dan wanita dilihat dari sudut non-biologis yaitu dari aspek sosial budaya maupun psikologis. Gender juga menjadi sebuah konsep kultural, berupaya membuat perbedaan (distinction) dalam hal peran, perilaku, mentalitas dan karakteristik emosional antara lelaki dan wanita yang berkembang dalam masyarakat (Siti Musdah, 2004:4) Dari beberapapenelitian mengenai gender yang telah dijalankan diantaranya tidak menunjukkan hasil yang konsisten. Penelitian yang dilakukan Ganda dan Christine (2016) mengenai kepatuhan pajak didapati bahwa tidak ada perbedaan kepatuhan perpajakan antara lelaki dan wanita, ia berpendapat baik lelaki mauoun wanita telah mendapatkan akses yang sama dalam pendidikan sehingga adanya asimilasi yang mendorong adanya persamaan persepsi, sama halnya dengan penelitian Kiryanto dan Villia (2013) mendapatkan bahwa variable ender tidak memiliki pengaruh yang signifikan terhadap motivasi memba- 
Ivalaili - 4

yar zakat, sementara Hairunnizam et al. (2007) mendokumentasikan bahwa wanita yang berkariri cenderung membayar zakat penghasilan daripada lelaki. Berdasarkan argument yang berbeda ini penelitian ini berpendapat bahwa:

H2: Terdapat hubungan gender dengan kepatuhan dalam berzakat.

\section{Tingkat Pendidikan}

Gunning dan Kohnstan telah mendefinisikan pendidikan sebagai pembentukkan diri secara etis sesuai dengan hati nurani, dari beberapa pengertian menyatakan bahwa pendidikan dapat mendorong seseorang dalam mengetahui potensi diri dan mengetahui hal yang patut dikerjakan agar meraih manfaat dunia dan akhirat. Penelitian mengenai pengaruh pendidikan mendapatkan bahwa semakin terbuka terhadapnilai-nilai baru yang berbeda dengan kebiasaan dan budaya. Penelitian Irfan dan Izatul (2012) berpendapat pendidikantidak bisa dijadikan variable yang dapat memisahkan objek pada grup membayar zakat dan grup yang tidak membayar zakat dengan baik, Maka penelitian ini berpendapat:

H3: Terdapat hubungan tingkat pendidikan dengan kepatuhan dalam berzakat.

\section{Tingkat Pendapatan}

Sumawan (2004:204) Pendapatan ialah suatu kompensasi yang diperoleh atau didapatkan melalui berbagai aktivitas pekerjaan yang sesuai dengan syariah oleh seorang dalam memenuhi kebutuhan hidup. (Boediono:1993) dikutip dalam Salmawati dan Meutia (2018) pada kenaikan jumlah pendapatan akan mempengaruhi pengeluaran seseorang , baik dalam bentik konsumsi maupun tabungan, termasuk dalam bentuk zakat, pendapatan seseorang dapat mendorong secara signifikan keputusan muzakki untuk mebayar zakat dan mendorong peningkatan besarnya nilai zakat. Penelitian ini menyatakan bahwa:

H4: Terdapat hubungan tingkat pendapatan dengan kepatuhan dalam berzakat.

\section{METODE PENELITIAN}

Penelitian ini merupakan kuantitatif studi dengan menggunakan data primer berupa kuesioner yang didistribusikan kepada sebagian masyarakat di Kota Tangerang. Teknik pengambilan sampel yang digunakan adalah nonprobability sampling dengan jenis purposive sampling yaitu teknik pengambilan sampel dengan pertimbangan responden adalah muzakki dengan total responden sebanyak 300 responden. Kuesioner didistribusikan kepada responden untuk mengetahui faktor religiusitas dan faktor-faktor demografi pada kepatuhan berzakat. Dimensi pada kuesionaire ini mengacu pada penelitian sebelumnya sebagai acuan Al-Mamun et al. (2014) Ganda Frisno et al. (2016) dengan beberapa perubahan. Penelitian ini menggunakan kepatuhan dalam berzakat. sebagai dependen variabel dan independen variabel terdiri dari religiusitas 
5 - AL-URBAN: Jurnal Ekonomi Syariah dan Filantropi Islam

Vol. 3, No. 1, Juni 2019

http://journal.uhamka.ac.id/index.php/al-urban

p-ISSN: 2580-3360 e-ISSN: 2581-2874

DOI: $10.22236 /$ alurban_vol3/is1pp1-12

Hal 1-12

dan faktor-faktor demografi pada pe- pok dengan jumlah responden terbannelitian ini yang diambil terbatas pada yak, yakni sebesar 61 persen, kelomgender, tingkat pendidikan dan tingkat pok umur kurang dari 24 tahun sebesari pendapatan. Untuk mengukur tingkat 21 persen, pada kelompok umur antara religiusitas, penelitian ini mengadopsi 35 tahun s.d 54 tahun sebesar 11 perspengukuran religiusitas yang dikem- en sedangkan persentase responden bangkan oleh Wan Ahmad et al. (2008) dengan umur di atas 55 tahun sebesar Pengukuran religiusitas terdiri dari 217 persen. Pada Penelitian ini tingkat item dibagi menjadi kedalam 4 bagian. pendapatan dikelompokkan menjadi 4 dimensi Iman, dimensi Akhlak, dimensi kelompok presentase responden dengan menjalankan ibadah wajib, dan dimen- pendapatan $\leq$ Rp.2.500.000 adalah 13 si menjalankan ibadah sunah, Analisis secara deskriptif dilakukan untuk menjawab pernyataan responden menggunakan skala likert yang memiliki nilai 1 sampai 4.

\section{HASIL DAN PEMBAHASAN}

Hasil kuesioner yang didistribusikan secara lengkap dijelaskan pada tabel 1. Terdapat 53 persen responden lelaki dan responden wanita sebesar 47 persen. Sebagian besar dengan pendidikan S1 sebesar 40 persen, tingkat DIII sebesar 20 persen responden, tingkat pendidikan S2 sebesar 31 persen, responden dengan tingkat pendidikan S3 sebesar 4.7 persen sedangkan pendidikan terakhir SMA hanya 2.3 persen. Berdasarkan kategori umur, kelompok umur 25 tahun s.d. 34 tahun merupakan kelompersen Responden dengan pendapatan Rp. 2.600.000- Rp. 3.500.000 adalah 55 persen Responden dengan pendapatan Rp. 3,600,000- Rp. 5.000.000 sebanyak 15 persen dan Responden dengan pengdapatan diatas Rp. 5.000.000 sebanyak 17 persen. Selanjutnya pada umumnya responden bekerja sebagai PNS sebesar 40 persen, Pegawai Swasta 33 persen responden, Pegawai BUMN sebesar 16 persen wirausaha sebesar 10 persen kemudian persentase responden yang telah sebesar 2 persen.

Penelitian ini menguji empat hipotesis secara langsung. Masing-masing hipotesis akan dijelaskan dalam beberapa tabel yang telah dilampirkan.

H1: Terdapat hubungan religiusitas dengan kepatuhan dalam berzakat. 
Ivalaili - 6

Tabel 1. Deskriptif Statistik pada Variable

Demografi

\begin{tabular}{|c|c|c|}
\hline & $N$ & $\%$ \\
\hline \multicolumn{3}{|l|}{ Gender } \\
\hline Pria & 159 & 53 \\
\hline Wanita & 141 & 47 \\
\hline \multicolumn{3}{|l|}{ Tingkat Pendidikan } \\
\hline SMA & 7 & 2.3 \\
\hline D3 & 60 & 20 \\
\hline S1 & 124 & 40 \\
\hline $\mathrm{S} 2$ & 95 & 31 \\
\hline S3 & 14 & 4.7 \\
\hline \multicolumn{3}{|l|}{ Umur } \\
\hline$\leq 24$ tahun & 63 & 21 \\
\hline 25 tahun-34 tahun & 185 & 61 \\
\hline 35 tahun -54tahun & 31 & 11 \\
\hline 55 tahun $\geq$ & 21 & 7 \\
\hline \multicolumn{3}{|l|}{ Tingkat Pendapatan } \\
\hline$\leq \mathrm{Rp} .2 .500 .000$ & 40 & 13 \\
\hline R.:.000:808000- Rp. & 166 & 55 \\
\hline R.B.0 $3.808000-\mathrm{Rp}$ & 45 & 15 \\
\hline Diatas Rp. 5.000.000 & 49 & 17 \\
\hline \multicolumn{3}{|l|}{ Jenis Pekerjaan } \\
\hline Wirausaha & 30 & 10 \\
\hline Pegawai Swasta & 93 & 33 \\
\hline BUMN & 50 & 16 \\
\hline PNS & 120 & 40 \\
\hline Pensiun & 7 & 2 \\
\hline \multicolumn{3}{|l|}{ Status Pernikahan } \\
\hline Lajang & 112 & 40 \\
\hline Menikah & 188 & 60 \\
\hline $\begin{array}{l}\text { Note: } n=300 \\
\text { Sumber data diolah }\end{array}$ & & \\
\hline
\end{tabular}


7 - AL-URBAN: Jurnal Ekonomi Syariah dan Filantropi Islam

Vol. 3, No. 1, Juni 2019

http://journal.uhamka.ac.id/index.php/al-urban

p-ISSN: 2580-3360 e-ISSN: 2581-2874

DOI: 10.22236/alurban_vol3/is1pp1-12

Hal 1-12

\section{Tabel 2. Deskriptif Statistik Religi usitas dan Kepatuhan Berzakat}

\begin{tabular}{|c|c|c|}
\hline & Mean & SD \\
\hline \multicolumn{3}{|l|}{ Variabel Religiusitas } \\
\hline 1. Sholat Fardhu lima kali dalam sehari & 3.941 & 0.243 \\
\hline 2. Sholat tepat waktu & 3.916 & 0.288 \\
\hline $\begin{array}{l}\text { 3. Saya merasa bersalah apabila meninggalkan } \\
\text { sholat }\end{array}$ & 3.900 & 0.341 \\
\hline 4. Sholat Berjamaah dimasjid & 2.622 & 0.816 \\
\hline 5. Percaya pada Allah termasuk 6 Rukun Iman & 3.904 & 0.380 \\
\hline 6. Percaya adanya reward dan punishment & 3.886 & 0.345 \\
\hline 7. Bersikap Jujur & 3.720 & 0.556 \\
\hline 8. Mengucapkan dan membalas salam & 3.801 & 0.479 \\
\hline 9. Puasa pada Bulan Ramadhan & 3.546 & 0.643 \\
\hline 10. Menjalankan Puasa Sunnah & 3.842 & 0.410 \\
\hline 11. Mendirikan Sholat Sunnah Dhuha & 3.187 & 0.707 \\
\hline 12. Mendirikan Sholat Sunnah Rawatib & 3.223 & 0.673 \\
\hline 13. Membaca Alqur'an/ Berzikir & 3.188 & 0.703 \\
\hline 14. Menghormati tetangga & 3.790 & 0.509 \\
\hline 15. Menghormat orang lebih tua & 3.438 & 0.644 \\
\hline 16. Tidak mendahului kepentingan Pribadi & 3.286 & 0.589 \\
\hline 17. Saya menepati janji & 3.151 & 0.673 \\
\hline 18. Saya menjalin Silaturahmi & 3.257 & 0.666 \\
\hline 19. Saya menjaga Aurat & 3.312 & 0.607 \\
\hline $\begin{array}{l}\text { 20. Saya mengkonsumsi makanan dan minuman } \\
\text { halal }\end{array}$ & 3.941 & 0.243 \\
\hline 21. Saya berinfaq dan bersedekah & 3.916 & 0.288 \\
\hline \multicolumn{3}{|l|}{ Kepatuhan dalam Berzakat } \\
\hline $\begin{array}{l}\text { 1. Saya setiap tahun/ sesuai haul dan nisab mem- } \\
\text { bayar zakat untuk mensucikan harta dan jiwa }\end{array}$ & 3.778 & 0.574 \\
\hline $\begin{array}{l}\text { 2. Saya membayar setiap tahun/ sesuai haul dan } \\
\text { nisab agar mendapatkan kemuliaan }\end{array}$ & 3.138 & 0.644 \\
\hline Sumber data diolah 2018 & & \\
\hline
\end{tabular}

Tabel 2. menunjukkan Mean dan Standar Deviasi (SD) untuk item religiusitas Islam dan pengukuran perilaku kepatuhan berzakat. Hampir semua item yang berkaitan dengan religiusitas Islam memiliki skor rata-rata di atas 3,00, Pada pernyataan "Percaya pada Allah dan 6 Rukun Iman" menunjukkan Mean 3.904 dan SD 0.380 dan "Percaya 
Ivalaili - 8

adanya pahala dan dosa" menunjukkan Mean 3.886 dan SD 0.345. ini menunjukkan bahwa mayoritas responden memiliki nilai-nilai agama Islam yang kuat. Skor pada pernyataan "Saya membayar setiap tahun/ sesuai haul dan nisab agar mendapatkan kemuliaan" menunjukkan mean 3.138 menyiratkan bahwa beberapa responden membayar zakat karena kewajiban agama, dan bukan karena untuk mendapatkan suatu penghargaan atau kemuliaan.
Pada Tabel 3. Diperoleh nilai koefisien Cronbach Alpha pada masing-masing dimensi lebih besar dari 0.6 sehingga alat ukur yang digunakan adalah reliable. Selanjutnya korelasi analisis digunakan untuk menguji kekuatan dan arah hubungan antara dua variable. Hasil pengujian korelasi analisis untuk menguji kekuatan dan arah hubungan kedua variable tersebut dijelaskan secara lengkap pada tabel 3 .

Tabel 3. Dimensi Religiusitas

\begin{tabular}{|l|l|l|}
\hline Dimensi & Loading & Cronbach's $\alpha$ \\
\hline 1. Iman & & \\
Percaya pada Allah termasuk 6 Rukun Iman & 0.854 & 0.809 \\
\hline Percaya adanya reward dan punishment & 0.825 & \\
\hline Saya merasa bersalah apabila meninggalkan sholat & 0.764 & \\
\hline $\begin{array}{l}\text { 2. Akhlak } \\
\text { Mengucapkan dan membalas salam }\end{array}$ & 0.794 & 0.787 \\
\hline Saya menjalin Silaturahmi & 0.750 & \\
\hline Menghormat orang lebih tua & 0.702 & \\
\hline Saya menepati janji & 0.731 & \\
\hline Tidak mendahului kepentingan Pribadi & 0.703 & \\
\hline Bersikap Jujur & 0.642 & \\
Mengucapkan dan membalas salam & 0.774 & \\
Menghormati tetangga & 0.854 & \\
\hline 3. Wajib & & \\
Sholat Fardhu lima kali dalam sehari & 0.825 & 0.776 \\
\hline Sholat tepat waktu & 0.784 & \\
\hline Puasa pada Bulan Ramadha & 0.854 & \\
\hline Mengkonsumsi makanan dan minuman halal & 0.794 & \\
Saya Menjaga Aurat & 0.782 & \\
\hline
\end{tabular}


9 - AL-URBAN: Jurnal Ekonomi Syariah dan Filantropi Islam

Vol. 3, No. 1, Juni 2019

http://journal.uhamka.ac.id/index.php/al-urban

p-ISSN: 2580-3360 e-ISSN: 2581-2874

DOI: 10.22236/alurban_vol3/is1pp1-12

Hal 1-12

\begin{tabular}{|l|l|l|}
\hline Dimensi & Loading & Cronbach's $\alpha$ \\
\hline 4. Sunnah & & \\
Saya solat Berjamaah di Masjid & 0.774 & 0.778 \\
\hline Saya berinfaq dan bersedeqah & 0.666 & \\
Membaca Alqur'an/ Berzikir & 0.782 & \\
Mendirikan Sholat Duha & 0.705 & \\
Mendirikan Sholat Rawatib & 0.750 & \\
\hline
\end{tabular}

Sumber data diolah 2018

Tabel 4. Uji Korelasi

\begin{tabular}{lllll|}
\hline \multicolumn{1}{c}{ Variabel } & \multicolumn{3}{c}{ Kruskal- Wallis } & \multicolumn{2}{c}{ Spearman } \\
\hline & Chi- Square & Asymp.Sig & Coef. & Sig \\
Religiusitas & 8.720 & 0.012 & $0.212 * *$ & 0.001 \\
Gender & 0.101 & 0.851 & -0.018 & 0.831 \\
Pendidikan & 0.740 & 0.490 & $-0.059 * *$ & 0.491 \\
Pendapatan & 11.573 & 0.021 & $0.168 * *$ & 0.003 \\
Signifikan **5\%, *10\% & & & \\
\hline Sumber data diolah 2018
\end{tabular}

Sumber data diolah 2018

H2: Terdapat hubungan gender dengan kepatuhan dalam berzakat

Berdasarkan Tabel 4. H2. ditolak karena tidak ada perbedaan kepatuhan berzakat pada lelaki dan wanita Uji Kruskal- Wallis p-value (Asymp. Sig) 0.851>0.05. Pada Uji Korelasi Spearman mendapatkan hasil tidak signifikan $(0.831>0.05)$ dengan $(r=-0.018)$. Hasil ini inkonsisten dengan anggapan yang didokumentasikan dalam penelitian sebelumnya tentang zakat yang berpendapat bahwa wanita berkarir lebih cenderung membayar zakat atas penghasilan daripada lelaki (Hairunnizam et al, 2007).

H3: Terdapat hubungan tingkat pendidikan dengan kepatuhan dalam berzakat.

H3 ditolak karena tidak ada perbedaan kepatuhan berzakat antara responden dari latar belakang pendidikan Uji Kruskal-Walli, p-value (Asymp. Sig) bernilai $0.490>0.05$ Uji Korelasi Spearman menunjukkan tidak ada korelasi $(p=0.491>0.05)$ dengan $(r=0.059)$ dengan arah hubungan yang positif. Hal ini dapat sejalan dengan penelitian Irfan dan Izatul, (2012) Variabel pendidikan berdasarkan tingkat pendidikan dari urutan pendidikan tertinggi sampai terendah belum bisa dijadikan variabel yang dapat memisahkan objek pada grup membayar zakat dan grup yang tidak membayar zakat dengan baik

H4: Terdapat hubungan tingkat pendapatan dengan kepatuhan dalam berzakat.

H4 diterima ada perbedaan signifikan kepatuhan berzakat antara responden 
Ivalaili -10

yang tingkat pendapatannya berbeda. mungkin untuk mematuhi zakat. Dilihat Uji Kruskal-Walli, p-value (Asymp. tiga dimensi Ibadah Wajib dan Sunnah Sig) $0.021<0.05$. Uji korelasi Spearman menunjukkan adanya korelasi signifikan pada tingkat pendapatan $(\mathrm{p}=0.003<$ $0.05)$ dengan $(\mathrm{r}=0.168)$ dengan arah hubungan yang positif. Hasil penelitian ini sejalan dengan penelitian yang telah dijalankan Satrio (2015) menyatakan bahwa variabel/ konstruk pendapatan seseorang mempunyai pengaruh terhadap minat masyarakat membayar zakat di lembaga amil zakat secara signifikan, sebagai tambahan penelitian lain mengenai kepatuhan membayar zakat seperti yang dilakukan oleh Nur Azura, et.al. (2005), penelitian ini menemukan bahwa tahap sosial dan jumlah tanggungan memberi pengaruh yang signifikan terhadap perilaku kepatuhan individu dalam mengeluarkan zakat pendapatan.

\section{SIMPULAN}

Kesimpulan penelitian ini menguji pengaruh religiusitas, faktor-faktor demografi terdirir dari gender, tingkat pendidikan dan tingkat pendapatan pada kepatuhan berzakat. Konsisten dengan penelitian sebelumnya, kepatuhan membayar zakat, penelitian Mukhlis dan Irfan (2013) telah membuktikan bahwa faktor keimanan berpengaruh terhadap kepatuhan berzakat, penelitian ini menunjukkan bahwa religiusitas Islam memiliki pengaruh signifikan pada perilaku kepatuhan zakat, menunjukkan bahwa umat Islam dengan nilai-nilai agama yang kuat atau lebih tinggi sangat dan akhlaq adalah faktor pendorong untuk perilaku kepatuhan zakat ini menunjukkan bahwa umat Islam dengan komitmen agama yang kuat akan mematuhi kewajiban-kewajibannya.

Berkenaan dengan gender tidak menunjukkan ada perbedaan ini memberikan pemahaman bahwa baik lelaki maupun wanita memiliki kewajiban yang sama dalam berzakat. Dalam hal latar belakang pendidikan tidak ada perbedaan kepatuhan berzakat antara responden dari latar belakang pendidikan namun memiliki hubungan yang positf menunjukkan bahwa semakin tinggi latar belakang pendidikan seseorang maka kepatuhan berzakat akan semakin tinggi selanjutnya hubungan postif dan signifikan ditunjukkan pada tingkat pendapatan yang berarti bahwa kepatuhan berzakat dalam diri seseorang akan semakin lebih tinggi seiring bertambahnya pendapatan mereka.

Peningkatan kepatuhan muzakki dalam berzakat perlu mendapat dukungan dari berbagai komponen baik pemerintah, Badan Amil Zakat dan Lembaga Amil Zakat dengan melakukan sosialisasi, edukasi dan melalui literasi kepada masyarakat, selain itu peran BAZNAS dan LAZ juga harus menjangkau muzakki dan mustahik seluas-luasnya agar dapat merealisasikan pengumpulan dana zakat sesuai dengan target poten- 
11 - AL-URBAN: Jurnal Ekonomi Syariah dan Filantropi Islam

Vol. 3, No. 1, Juni 2019

http://journal.uhamka.ac.id/index.php/al-urban

p-ISSN: 2580-3360 e-ISSN: 2581-2874

DOI: 10.22236/alurban_vol3/is1pp1-12

Hal 1-12

sinya.

Batasan dalam penelitian ini antaralain hanya mencakup 300 reponden berdasarkan data yang dikumpulkan melalui kuisioner dan temuan pada penelitian ini tidak dapat digeneralisasikan mengingat responden pada penelitian ini hanya terbatas muzakki di kota Tangerang yang menjangkau lapisan masyarakat luas. Batasan lainnya adalah penelitian ini tidak mensurvei mengapa responden tidak mematuhi kewajiban zakat atau hambatan mereka terkait kepatuhan dalam berzakat

\section{REFERENSI}

Abdul Azis Ahyadi. (2005). Psikologi Agama: Kepribadaian Muslim Pancasila. Bandung: Sinar Baru Algensindo.

Ahmad Mukhlis, Irfan Syauqi Beik. (2013). Analisis Faktor-faktor yang Memengaruhi Tingkat Kepatuhan Membayar Zakat: Studi Kasus Kabupaten Bogor. Jurnal Al Murazaah. Vol 1, No 12013. Indonesia: Institut Pertanian Bogor.

Ancok, D dan Suroso, F. (2001). Psikologi Islami : Solusi Islam Atas Problem-Problem Psikologi. Yogyakrta: Pustaka Pelajar Anugerah Azman.

Al-Mamun, Abdullah, Harry Entebang, Shazali Abu Mansor, Qaiser Rafique Yasser, dan Thurai Murugan Nathan. (2014). The Impact of

Bo

Boediono, (1993), Ekonomi Makro, Yogyakarta : BPFE UGM,.

Ganda Frisno Pasaribu dan Christine Tjen, (2016), "Dampak Faktor-Faktor Demografi Terhadap Kepatuhan Perpajakan di Indonesia" Berkala Akuntansi dan Keuangan Indonesia, Vol. 1, No. 2 (2016): 145-162. Indonesia: Universitas Airlangga

Irfan Syauqi Beik dan Izzatul Mabniyyah Alhasanah (2012), "Analisis Faktor-Faktor Yang Mempengaruhi Tingkat Partisipasi dan Pemilihan Tempat Berzakat Dan Berinfak". Jurnal Ekonomi \& Keuangan Islam. Vol.2 No. 1, Januari 2012: 64-75 Indonesia: Institut Pertanian Bogor.

Kiryanto dan Villia Nikmatul khasanah (2013). “Analisis Karakteristik Muzakki dan Tata Kelola LAZ Terhadap Motivasi Membayar Zakat Penghasilan." Jurnal Akuntansi Indonesia, Vol. 2 No. 1 Januari 2013, Hal. 51-64. Indonesia: Universitas Islam Sultan Agung Semarang

Mohd Rizuan, A.K., Zulkifli, Z.A., Juliana Anis, R. and Khairul Nizam, S. (2014), "Factors influencing a business towards zakat payment in Malaysia", International Journal of Science Commerce and $\mathrm{Hu}-$ 
Ivalaili -12

manities, Vol. 2 No. 3 2014, pp. 147-156.

Muda, M., A. Marzuki, dan A. Shaharudin. (2006). Factors Influencing Individual Participation In Zakat Contribution: Exploratory Investigation. Kertas kerja pada Seminar for Islamic Banking and Finance 2006, Agustus 2006, Malaysia: Kuala Lumpur.

Muzakkir. (2013). Hubungan Religiusitas dengan Perilaku Prososial. Jurnal Diskursus Islam. Vol. 1 No. 3, Desember 2013. Indonesia: UIN Alauddin.

Salmawati dan Meutia Fitri. (2018). Pengaruh Tingkat Pendapatan, religiusitas dan Kualitas Pelayanan Terhadao Minat Muzakki Membayar Zakat di Baituk Mal Kota Banda Aceh. Jurnal Ilmiah Mahasiswa Ekonomi Akuntansi, Vol. 3, No, 1 Tahun 2018 pp. 54-66. Indonesia: Universitas Syah Kuala.

Satrio, Eko. (2015). Analisis Faktor Pendapatan, Kepercayaan, Religiusitas dalam Mempengaruhi Minat Muzakki Membayar Zakat Penghasilan Melalui Lembaga Amil Zakat. Jurnal SNA, 1-22.

Nur Azura, S., A.W. Norazlina, dan
M.B. Nor Fadzlin. (2005). Gelagat kepatuhan pembayaran zakat pendapatan: kajian kes Universiti Utara Malaysia. Kertas Kerja yang dibentangkan pada Seminar Ekonomi dan Kewangan Islam, Malaysia : Jabatan Ekonomi Awam dan Kewangan Fakulti Ekonomi Universiti Utara Malaysia.

Sumarwan, U. (2004). Prilaku Konsumen Teori dan Penerapannya dalam Pemasaran. Bogor: Ghalia Indonesia.

Undang-Undang zakat.Undang-Undang republik Indonesia Nomor 38 Tahun 1999 Tentang Pengelolaan Zakat.

Wan Ahmad, W.M.,Rahman, Ab, Asmak, Ali,N.and Che Seman, Azizi (2008). Religiosity and banking selection criteria amongst Malays in Lembah Klang. Jurnal Syariah, Vol. 16 No. 2 2008, pp. 99-130 